\title{
Optimization by Thermodynamics in Time Finished of a Cold Store with Mechanical Compression of the Vapors
}

\section{Okotaka Ebale, B. Mabiala*, D. Nkounkou Tomodiatounga}

Laboratoire Mécanique, Energétique et Ingénierie, Chaire Unesco en Sciences de l'Ingénieur-Ecole Nationale Supérieure Polytechnique, Université Marien Ngouabi, Brazzaville, Congo

Email: *Bernamab@yahoo.com

How to cite this paper: Ebale, L.O., Mabiala, B. and Tomodiatounga, D.N. (2016) Optimization by Thermodynamics in Time Finished of a Cold Store with Mechanical Compression of the Vapor. Journal of Electronics Cooling and Thermal Control, 6, 139-152.

http://dx.doi.org/10.4236/jectc.2016.64013

Received: October 29, 2016

Accepted: December 17, 2016

Published: December 20, 2016

Copyright $\odot 2016$ by authors and Scientific Research Publishing Inc. This work is licensed under the Creative Commons Attribution International

License (CC BY 4.0).

http://creativecommons.org/licenses/by/4.0/

\begin{abstract}
This study made it possible to determine by the application of thermodynamics in finished time, the points of instruction necessary to the development of a regulation system for the rationalization of the power consumption in a cold store. These points were obtained by determining the optimal variations of temperature as well to the condenser and the evaporator corresponding to the minimum capacity absorptive by the compressor for a maximum COP.
\end{abstract}

\section{Keywords}

Thermodynamics in Finished Time, Rationalization of Energy, Maximum

Refrigerating Power, Optimal Variations of Temperature

\section{Introduction}

Response to the demands imposed by the market, of the directives related to the rational use of energy and the safeguarding of the environment, the design of the current cold stores requires to a certain extent, taking into account of various constraints, in particular: thermodynamic constraints (minimization of the irreversibilities); technological constraints (pressure losses, losses of fluid cooling) and economic constraints (value for money) [1]. The interaction between these multi-field constraints, poses a problem of optimization which can find its resolution in the application of thermodynamics in finished time, which by definition represents the thermodynamics of the real systems whose heat transfers with the tanks (evaporator and condenser) have external irreversibilities [2]. In refrigeration industry, this problem results in the maximization of the 
performance of the cold store in other words, the maximization of its coefficient of performance (refrigerating $\mathrm{COP}=$ production/consumption [3]). In the cold stores, the production of the real flow of heat is achieved by means of an evaporator; paradoxically, the ideal and reversible refrigerating cycle of Carnot whose refrigerating efficiency is maximum and of which the differences in temperature between the reserves and the fluid of the cycle are infinitesimal, delivers a null heat flow ([4] [5] [6] [7]). However, to deliver a heat flow not no-one, the heat-transferring surfaces and the time of contact with the tanks must be infinite, thus delivering a virtual refrigerating power. Obtaining a real refrigerating power, thus imposes heat-transferring surfaces and total coefficients of finished transfer, differences in temperatures with the finished tanks ([1] [8] [9]). Consequently, one obtains the time of contact between the fluid interns and the finished tanks. In addition, the transfer laws of heat of the two tanks make it possible to obtain heat flows according to the conductance and the differences in temperature; they easily allow the determination of the optimal values of temperature at the evaporator and the condenser for a minimal consumption of energy ([2] [5] [7]).

These optimal values will make it possible for the system of regulation to adapt the operation of the installation to the temperature variations for a COP maximum (refrigerating $\mathrm{COP}=$ production/consumption). The COP in addition expresses the viability of a refrigerating cycle. Optimization will consist in determining the optimal variation of temperature $\Delta \theta_{0}$ to the evaporator corresponding to a minimal consumption of energy to the compressor $\dot{W}_{\text {min }}$ for obtaining a maximum refrigerating flow [10] [11]. The resolution of the problem will require the development of a system of equations bringing into playing the equations of the energy assessment, entropy and of heat transfer. A transformation of the sizes dimensioned into a dimensional size will facilitate the mathematical treatment of optimization of the data of the system of equations $\Delta \theta_{0}$ and $\Delta \theta_{c}$.

Figure 1 presents the T-S diagram of the endoreversible ideal cycle but exoirreversible, namely that one neglects the internal irreversibilities and one considers only the irreversibilities due to the differences of temperature $\Delta \theta_{0}$ and $\Delta \theta_{c}$ with the reserves in heat which are respectively the evaporator and the condenser. The technological and scientific interest is not only the determination of the points of instruction necessary to the development of a system regulation for the rationalization of the power consumption by the cold store using a multi-field method but especially taking into account of the irreversibilities inherent in its operation.

\section{Material and Method}

\section{- Material}

The cold store Figure 2 is a group of production of indicated ice-cold water: STANDARD AQUACIATPOWER LD 1800BV R410A. This installation equips the refrigerating system with the air conditioning of the Bank of central Africa with Brazzaville.

Technical data of the installation: 


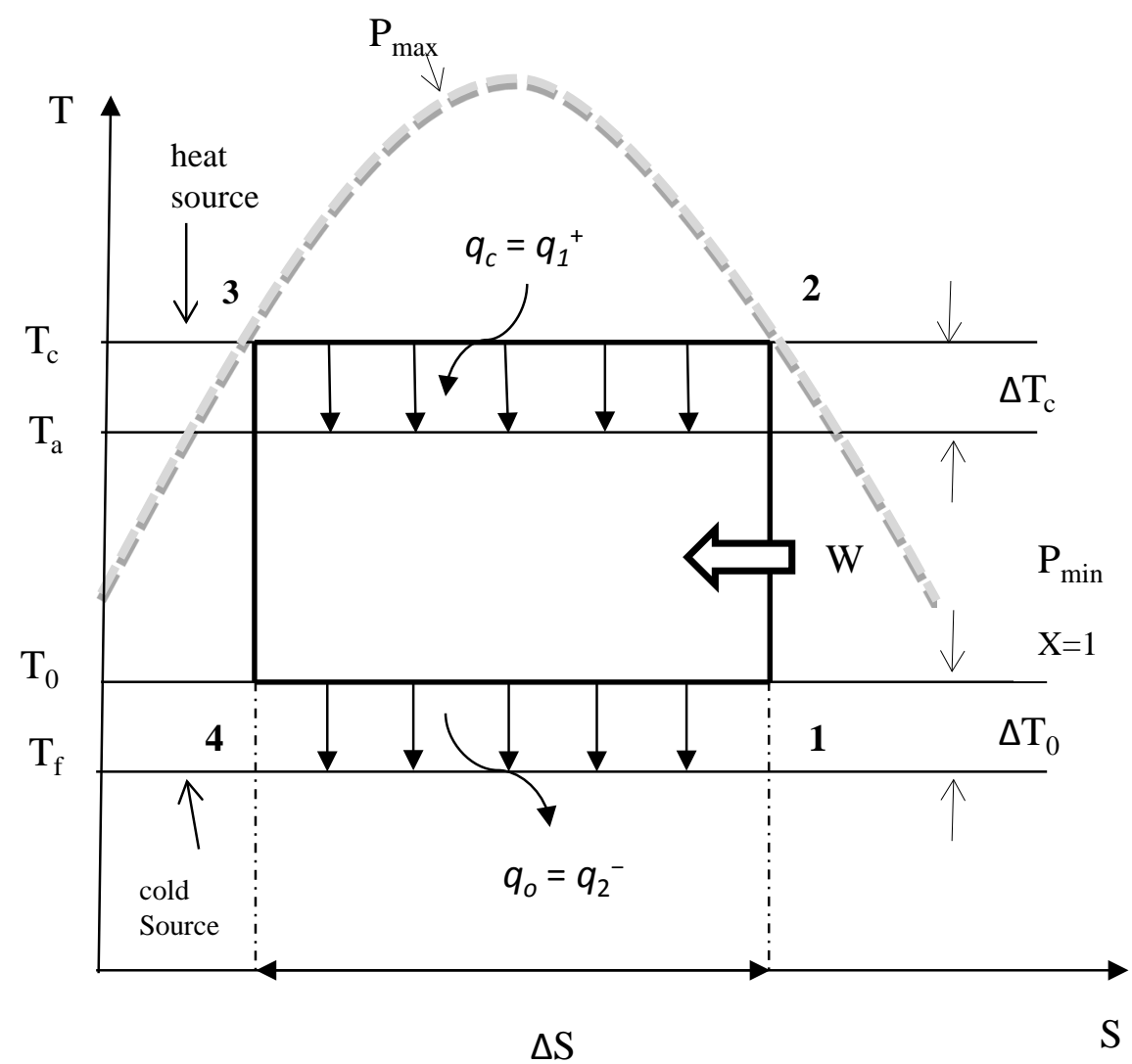

Figure 1. Diagram $T-S$ (T: the temperature and $S$ : entropy).

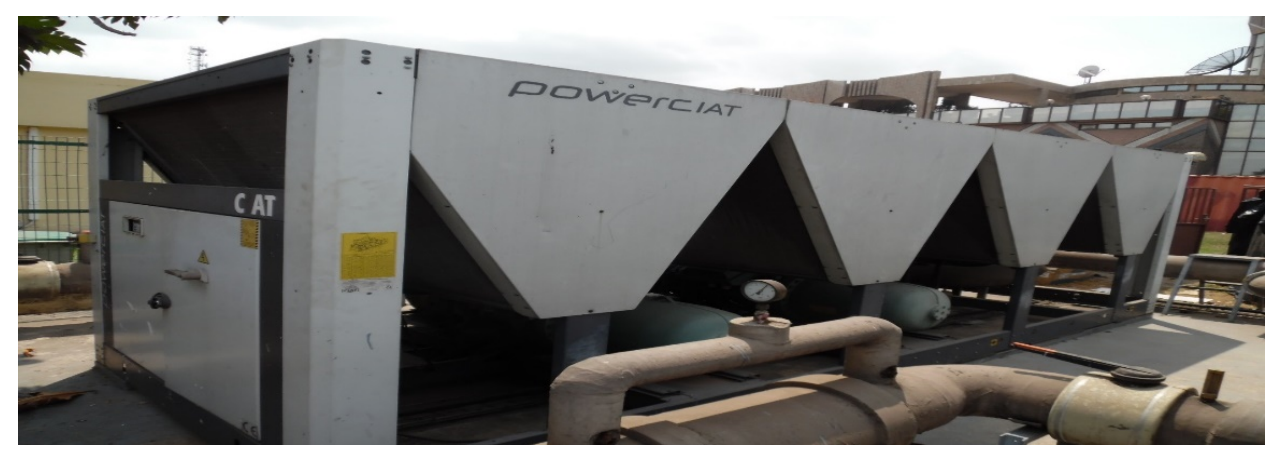

Figure 2. Cold store AQUACIATPOWER LD 1800BV standard R410A.

- Refrigerating power: $497.6 \mathrm{kw}$;

- Total thermal conductance: $118,657 \mathrm{~W} / \mathrm{k}$;

- Power of the condenser: $666 \mathrm{~kW}$;

- Temperature of the refrigerant: $280 \mathrm{~K}$;

- Coefficient of performance COP: 2.95;

- Room temperature: $308 \mathrm{~K}$.

\section{- Method for Calculation}

The operation of the cold stores with mechanical compression of the vapors has for cycle of reference, the ideal cycle of reversed Carnot. In accordance with the second principle of thermodynamics: heat cannot pass from the cold source of $T_{f}$ temperature to the hot spring of temperature $\mathrm{T}_{\mathrm{a}}$ without consuming work of the external medium.

The ideal cycle of reversed Carnot is reversible as well internal as (Equation (1)) ex- 
ternal in other words the processes of compression and of relaxation are with constant entropy and the transfer of heat between the fluid and the source is carried out with infinitesimal differences in temperature. A multi-field analysis of the refrigerating cycle of Carnot highlights the increase in the surface of transfer of heat necessary to the process of vaporization and condensation as the differences in temperature are reduced, is:

$$
Q=k \cdot A \cdot \Delta T
$$

with: Exchanged total $Q=$ heat; $k=$ heat exchange coefficient; $\Delta T=$ difference in temperature; $A=$ thermal heat-transferring surface.

When the transfer of heat takes place in extreme cases reversible of way, we have $\Delta T->d T$, then the heat-transferring surface $A->\infty$. The run time of the fluid in heat exchangers, (the condenser and the evaporator), tends towards the infinite one. Thus, for a heat-transferring surface of heat and a coefficient of exchange given, we note that the refrigerating power is cancelled.

On the other hand, for an installation producing a real heat flow $Q_{0}$ to the evaporator, the transfer of heat supposes the existence of a finished difference $\Delta T$ in temperature, the cycle of Carnot is irreversible external and the time of contact of the fluid with the sources of heat of surface $A$ limited also has a finished value. The irreversible optimization of cycle will consist in maximizing its performance by the maximization of its coefficient of performance.

The energy assessment of the installation is given by expression (2):

$$
W=q_{c}-q_{0}
$$

And the coefficient of performance of the installation, by Equation (3):

$$
\mathrm{COP}_{c}=\frac{q_{0}}{W}=\frac{q_{0}}{q_{c}-q_{0}}=\frac{1}{\frac{q_{c}}{q_{0}}-1}=\frac{1}{\frac{T_{c}}{T_{0}}-1} \leq 1
$$

It is observed that for a mass throughput of the refrigerating agent, the energy assessment can be also written in the form of Equation (4):

$$
\dot{m} W=\dot{m}\left|q_{c}\right|-\dot{m} q_{0}
$$

If one poses $\dot{m} W=\dot{W} ; \quad \dot{m}\left|q_{c}\right|=\dot{Q}_{c} ; \quad \dot{m} q_{0}=\dot{Q}_{0}$, the energy assessment becomes:

$$
\dot{W}=\left|\dot{Q}_{c}\right|-\dot{Q}_{0}:
$$

The entropic assessment as for him is written by Equation (6):

$$
\frac{T_{c}}{T_{0}}=\frac{\left|q_{c}\right|}{q_{0}}=>\frac{q_{0}}{T_{0}}=\frac{\left|q_{c}\right|}{T_{c}}
$$

The equations of heat transfer to the evaporator and the condenser are given by expressions (7) and (8):

$$
\dot{Q}_{0}=k_{0} A_{0} \Delta T_{0} ;
$$

with $K_{0}=k_{0} A_{0}$ and $\Delta T_{0}=T_{f}-T_{0}$ 


$$
\begin{gathered}
\Rightarrow \dot{Q}_{0}=K_{0} \Delta T_{0} \\
\dot{Q}_{c}=k_{c} A_{c} \Delta T_{c} ;
\end{gathered}
$$

with $K_{c}=k_{c} A_{c} ; \Delta T_{c}=T_{c}-T_{a}$

$$
\Rightarrow \dot{Q}_{c}=K_{c} \Delta T_{c}
$$

From two Equations (7) and (8), it results the entropic expression (9):

$$
\frac{\dot{Q}_{0}}{T_{0}}=\frac{\dot{Q}_{c}}{T_{c}}
$$

The dimensional notations are declined as it follows:

$$
\tau=\frac{T_{a}}{T_{f}} ; \theta_{0}=\frac{\Delta T_{o}}{T_{f}} ; \theta_{c}=\frac{\Delta T_{c}}{T_{a}}
$$

The parameters to be taken into account for the optimization of the installation are the following ones: $\dot{Q}_{0}, K, T_{o}, T_{c}$.

$$
\dot{Q}_{0}=K_{0} \Delta T_{0}=K_{0} T_{f} \theta_{0}=\text { cte; } K=K_{0}+K_{c}=\text { cteet } A=A_{0}+A_{c}
$$

The variables to be taken into account for the optimization of the installation are the following ones: Independent variables: $\theta_{0}$ and $\theta_{c}$; Dependent variables: $K_{0}$ and $K_{c}$. The transformation of the dimensioned sizes of the installation into a dimensioned size enables us to obtain the expressions of:

- A dimensional refrigerating power (Equation (12)):

$$
\bar{Q}_{0}=\frac{\dot{Q}_{0}}{K T_{f}}=\bar{K}_{0} \theta_{0}=\text { cte }
$$

$$
\text { with } \dot{Q}_{0}=K T_{f} \frac{K_{0}}{K} \theta_{0} \text { where } \bar{K}_{0}=\frac{K_{0}}{K} \epsilon(0 ; 1)
$$

- A dimensional calorific power of the condenser (Equation (13)):

$$
\begin{gathered}
\bar{Q}_{c}=\frac{\dot{Q}_{c}}{K T_{f}}=\left(1-\bar{K}_{0}\right) \tau \theta_{c}=\left(1-\frac{\bar{Q}_{0}}{\theta_{0}}\right) \tau \theta_{c} \\
\text { with } Q_{c}=K_{c} \Delta T_{c}=\frac{K_{c}}{K} \times K \times T_{f} \times \frac{\Delta T_{c}}{T_{a}} \times \frac{T_{a}}{T_{f}}=K T_{f} \frac{K-K_{0}}{K} \tau \theta_{c}
\end{gathered}
$$

- A dimensional mechanical work is:

$$
\bar{W}=\frac{\dot{W}}{K T_{f}}=\bar{Q}_{c}-\bar{Q}_{0}=\left(1-\frac{\bar{Q}_{0}}{\theta_{0}}\right) \tau \theta_{c}-\bar{Q}_{0}
$$

- The coefficient of performance becomes:

$$
\frac{1}{\mathrm{COP}_{c}}=\frac{\bar{W}}{\bar{Q}_{0}}=\left(\frac{1}{\bar{Q}_{0}}-\frac{1}{\theta_{0}}\right) \tau \theta_{c}-1
$$

That is to say:

$$
\mathrm{COP}_{c}=\frac{1}{\left(\frac{1}{\bar{Q}_{0}}-\frac{1}{\theta_{0}}\right) \tau \theta_{c}-1}
$$


By replacing the notations previously established in the entropic equations, we obtain:

$$
\frac{\dot{Q}_{0}}{T_{f}-\Delta T_{0}}=\frac{K_{c} \Delta T_{c}}{T_{a}+\Delta T_{c}}
$$

However $\Delta T_{0}=T_{f} \theta_{0} ; \Delta T_{c}=T_{a} \theta_{c}$ and $K_{c}=K-K_{0}$.

One has:

$$
\begin{aligned}
& \frac{\dot{Q}_{0}}{T_{f}-T_{f} \theta_{0}}=\frac{\left(K-K_{0}\right) T_{a} \theta_{c}}{T_{a}+T_{a} \theta_{c}} \\
\Rightarrow & \frac{\dot{Q}_{0}}{T_{f}\left(1-\theta_{0}\right)}=\frac{\left(K-K_{0}\right) T_{a} \theta_{c}}{T_{a}\left(1+\theta_{c}\right)}
\end{aligned}
$$

By simplifying the room temperature of Equation (20), then by dividing the equation by the coefficient of heat exchange total $K$, one has:

$$
=>\frac{\dot{Q}_{0}}{K T_{f}\left(1-\theta_{0}\right)}=\frac{\left(K-K_{0}\right)}{K} \frac{\theta_{c}}{1+\theta_{c}}
$$

However, $\bar{Q}_{0}=\frac{\dot{Q}_{0}}{K T_{f}}$ and $\bar{K}=\frac{K_{0}}{K}$, ones has:

$$
\frac{\bar{Q}_{0}}{1-\theta_{0}}=\left(1-\bar{K}_{0}\right) \frac{\theta_{c}}{1+\theta_{c}}
$$

In addition, it is known that $\bar{Q}_{0}=\bar{K} \theta_{0}=>\bar{K}=\frac{\bar{Q}_{0}}{\theta_{0}}$ Equation (22) is still written:

$$
\frac{\bar{Q}_{0}}{1-\theta_{0}}=\left(1-\frac{\bar{Q}_{0}}{\theta_{0}}\right) \frac{\theta_{c}}{1+\theta_{c}}
$$

In other words Equation (23), can be still written in the form:

$$
\frac{1}{\theta_{c}}+1=\left(1-\theta_{0}\right)\left(\frac{1}{\bar{Q}_{0}}-\frac{1}{\theta_{0}}\right)
$$

It results from it that:

$$
\theta_{c}=\frac{1}{\left(1-\theta_{0}\right)\left(\frac{1}{\bar{Q}_{0}}-\frac{1}{\theta_{0}}\right)-1}
$$

Consequently after substitution $\theta_{c}$ inside Equation (17) of the coefficient of performance (COP), we obtain:

$$
\operatorname{COP}_{C}=\frac{1}{\frac{\frac{1}{\bar{Q}_{0}}-\frac{1}{\theta_{0}}}{\left(1-\theta_{0}\right)\left(\frac{1}{\bar{Q}_{0}}-\frac{1}{\theta_{0}}\right)-1}-1}=f\left(\tau, \bar{Q}_{0}, \theta_{0}\right)
$$

where $\tau$ and $\bar{Q}_{0}$ are parameters, and $\theta_{0}$ the variable. 
After some simplifying transformations of the denominator $\mathrm{COP}_{c}$ of Equation (26):

$$
\left(1-\theta_{0}\right)\left(\frac{1}{\bar{Q}_{0}}-\frac{1}{\theta_{0}}\right)-1=\frac{1}{\bar{Q}_{0}}-\frac{1}{\theta_{0}}-\frac{\theta_{0}}{\bar{Q}_{0}}+1-1=\frac{1}{\bar{Q}_{0}}-\frac{1}{\theta_{0}}-\frac{\theta_{0}}{\bar{Q}_{0}}
$$

We obtain a final expression $\mathrm{COP}_{c}^{\text {irr }}$ naturally smaller than that of the cycle of Carnot $\mathrm{COP}_{c}^{r}$ which is the coefficient of performance of an ideal cycle. The maximum of the irreversible coefficient of performance is obtained for a minimum of consumption since the production of cold is imposed and thus remains invariant.

$$
\mathrm{COP}_{c}^{i r r}=\frac{\frac{1}{\bar{Q}_{0}}-\frac{1}{\theta_{0}}}{\frac{1}{\left(\frac{1}{\bar{Q}_{0}}-\frac{1}{\theta_{0}}\right)-\frac{\theta_{0}}{\bar{Q}_{0}}} \tau-1}=\frac{1}{\frac{\tau}{1-\frac{\theta_{0}^{2}}{\theta_{0}-\bar{Q}_{0}}}-1}<\operatorname{COP}_{c}^{r}=\frac{1}{\tau-1}
$$

Let us pose $\Psi=\frac{\theta_{0}^{2}}{\theta_{0}-\bar{Q}_{0}}$ and let us cancel its derivative

$$
\frac{\mathrm{d} \Psi}{\mathrm{d} \theta_{0}}=\frac{2 \theta_{0}\left(\theta_{0}-\bar{Q}_{0}\right)-\theta_{0}^{2}}{\left(\theta_{0}-\bar{Q}_{0}\right)^{2}}=0=>\theta_{0}^{\mathrm{opt}}=2 \bar{Q}_{0}
$$

The value which cancels this derivative makes it possible us to obtain the maximum value and consequently the coefficient of performance $\mathrm{COP}_{c}$ becomes maximum:

$$
\Psi_{\max }=\frac{4 \bar{Q}_{0}^{2}}{\bar{Q}_{0}}=4 \bar{Q}_{0}
$$

And

$$
\begin{gathered}
\mathrm{COP}_{c}^{\mathrm{max}}=\frac{\frac{1}{\frac{\tau}{1-4 \bar{Q}_{0}}-1}}{\bar{Q}_{0}<\frac{1}{4}=0.25 ; \bar{Q}_{0}=\bar{K}_{0}^{\mathrm{opt}} \theta_{0}^{\mathrm{opt}}=>\bar{K}_{0}^{\mathrm{opt}}=\frac{1}{2}=0.5 \text { because } \theta_{0}^{\mathrm{opt}}=2 \bar{Q}_{0}}
\end{gathered}
$$

By replacing $\theta_{0}^{\text {opt }}=2 \bar{Q}_{0}$ in the expression of $\theta_{c}$ (Equation (25)), we obtain the optimal value $\theta_{c}^{\text {opt }}$, Equation (32):

$$
\theta_{c}^{\mathrm{opt}}=\frac{1}{\frac{1}{\bar{Q}_{0}}-\frac{1}{\theta_{0}^{\mathrm{opt}}}-\frac{\theta_{0}^{\mathrm{opt}}}{\bar{Q}_{0}}}=\frac{1}{\frac{1}{\bar{Q}_{0}}-\frac{1}{2 \bar{Q}_{0}}-2}=\frac{1}{\frac{1}{2 \bar{Q}_{0}}-2}=\frac{2 \bar{Q}_{0}}{1-4 \bar{Q}_{0}}
$$

We can express according to in the form:

$$
\theta_{c}^{\mathrm{opt}}=\frac{\theta_{0}^{\mathrm{opt}}}{1+2 \theta_{0}^{\mathrm{opt}}}
$$

What enables us to obtain:

- minimal a dimensional calorific power (Equation (34)):

$$
\bar{Q}_{c}^{\mathrm{min}}=\left(1-\frac{\bar{Q}_{0}}{\theta_{0}^{\mathrm{opt}}}\right) \tau \theta_{c}^{\mathrm{opt}}=\left(1-\frac{1}{2}\right) \tau \frac{2 \bar{Q}_{0}}{1-4 \bar{Q}_{0}}=\tau \frac{\bar{Q}_{0}}{1-4 \bar{Q}_{0}}
$$


- minimal a dimensional mechanical work (Equation (35)):

$$
\bar{W}_{\text {min }}=\bar{Q}_{c}^{\min }-\bar{Q}_{0}=\tau \frac{\bar{Q}_{0}}{1-4 \bar{Q}_{0}}-\bar{Q}_{0}=\bar{Q}_{0}\left(\frac{\tau}{1-4 \bar{Q}_{0}}-1\right)
$$

The coefficient of maximum irreversible performance of the installation (Equations (36) or (37)):

$$
\begin{gathered}
\frac{1}{\mathrm{COP}_{c \text { max }}^{i r r}}=\frac{\bar{W}_{\min }}{\bar{Q}_{0}}=\frac{\tau}{1-4 \bar{Q}_{0}}-1 \\
=>\mathrm{COP}_{c \max }^{i r r}=\frac{1}{\frac{\tau}{1-4 \bar{Q}_{0}}-1}
\end{gathered}
$$

If $\bar{Q}_{0}=0$ so $\mathrm{COP}_{c \max }=\frac{1}{\tau-1}$, what corresponds to the output of the ideal cycle of Carnot.

- and the output of the installation is the report of the performance coefficient of the ideal cycle of Carnot (Equation (38)):

$$
\eta=\frac{\mathrm{COP}^{\mathrm{irr}}}{\mathrm{COP}_{c}^{r}}
$$

\section{Results and Discussion}

Figure 3 is represented the curve of the evolution of the coefficient of performance of the reversible cycle of Carnot of the installation according to the a dimensional temperature $\theta_{0}$ [3] [7]. It is noted obviously that this curve has a constant evolution more especially as heat exchange with the sources of heat (evaporator condenser) are carried

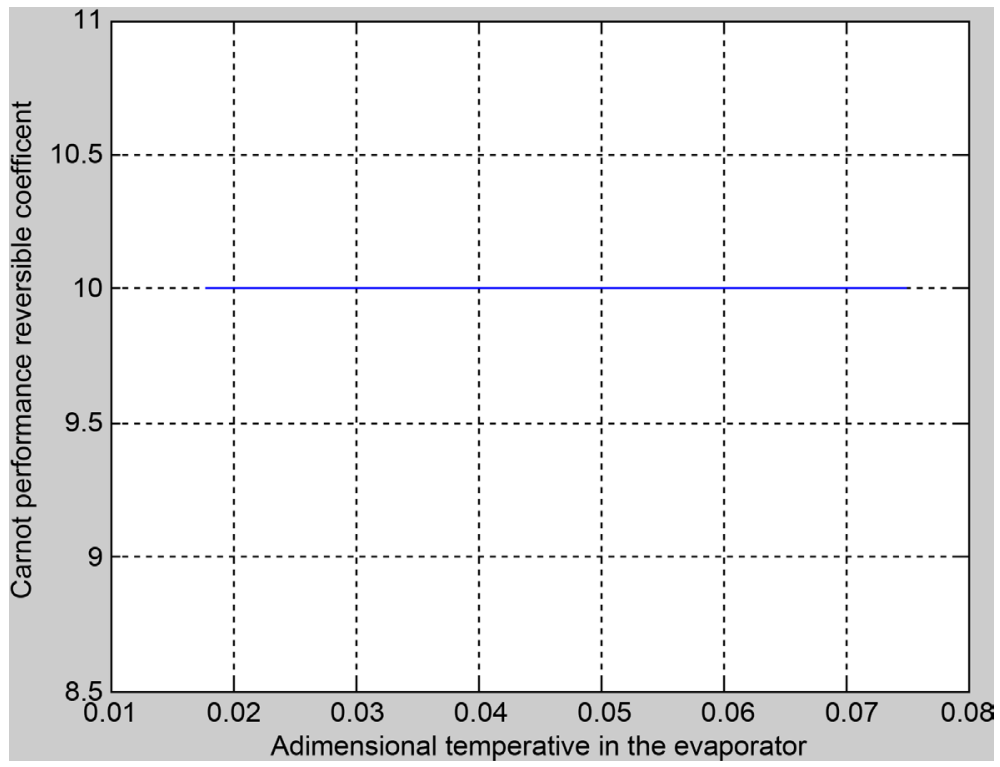

Figure 3. Evolution of the performance coefficient of the Carnot reversible cycle of the installation according to $\theta_{0}$. 
out in an isothermal way, [5] [6] [8]. Consequently, the coefficient of performance C.O.P depends only on the a dimensional report $\tau=$ When well even the value of the C.O.P would be maximum compared to that real as Figure 3 indicates it, the refrigerating flow produced by the installation under the conditions of reversibility remains virtual [5] [6]. In opposition to the reversible cycle of Carnot, Figure 4 presents the evolution of the coefficient of performance of the irreversible cycle of Carnot of the installation whose irreversibilities caused by differences in temperature have the evaporator and with the condenser produces a real refrigerating flow, Figure 1 [1] [8]. The evolution of the COP of the installation in function de $\theta_{0}$ is not constant any more. It presents a maximum corresponding has a minimum of energy expense Figure 5. The evolution of the output of the installation compared to the cycle of Carnot represented in Figure 6 also presents a maximum. This situation corresponds to the optimal differences of temperature $=8.38 \mathrm{~K}$ having the evaporator and respectively $=0.0318 \mathrm{~K}$ with the condenser. The power absorptive by the compressor indicates for these same optimal values a minimal value for the permanent evacuation of the heat flow imposed of the cold room corresponding to a minimum of heat flow evacuated to Figure 7 condenser. Thus, a distance beyond the optimal point of instruction during the operation of the installation due to the temperature variations involves an increase in the losses (external irreversibility) and implicitly a reduction of the output of the installation.

So that the installation produces a real heat flow $\dot{Q}_{0}=k_{0} A_{0} \Delta T_{0}$ to the evaporator, the transfer of heat imposes the existence of a variation in temperature. However, when this variation of temperature $\Delta T_{0} \rightarrow 0$, we have $\dot{Q}_{0}=0$ and the coefficient of

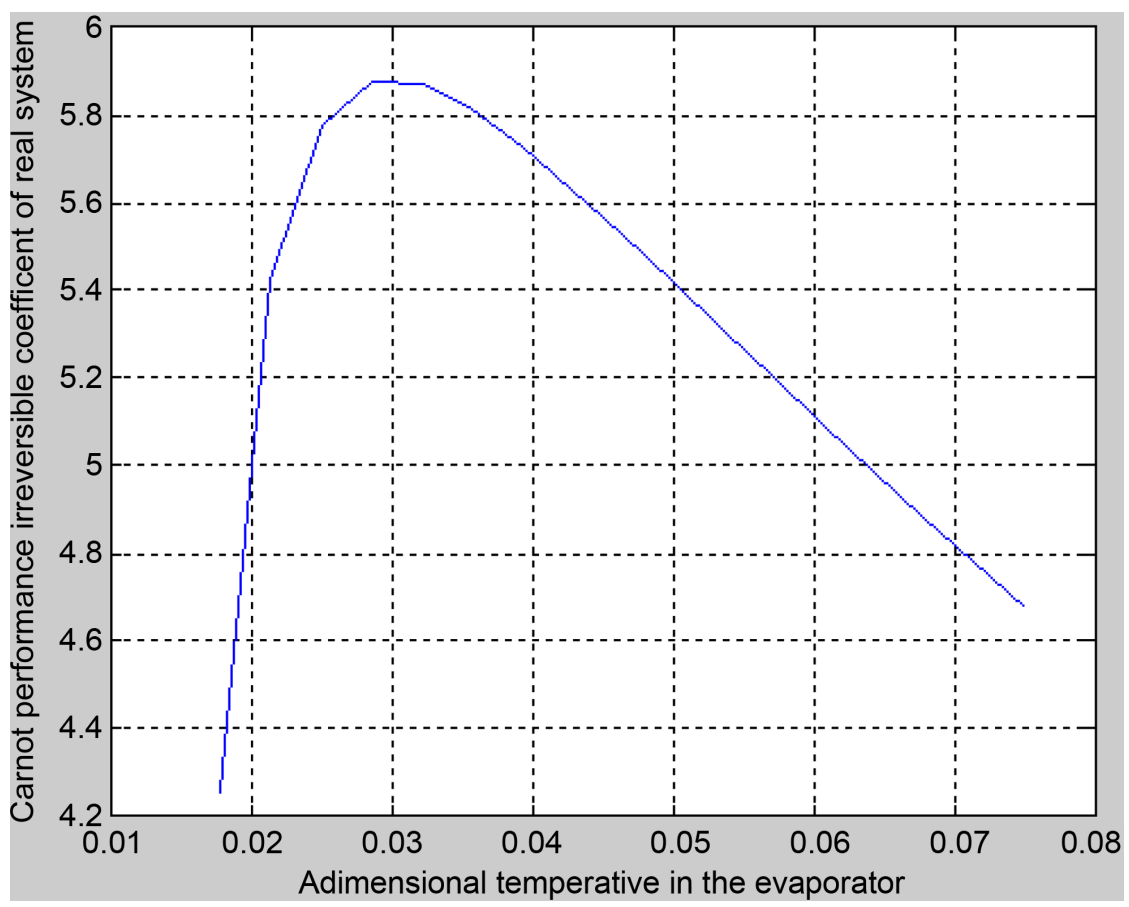

Figure 4. Evolution of the real performance coefficient of the installation cycle according to $\theta_{0}$. 


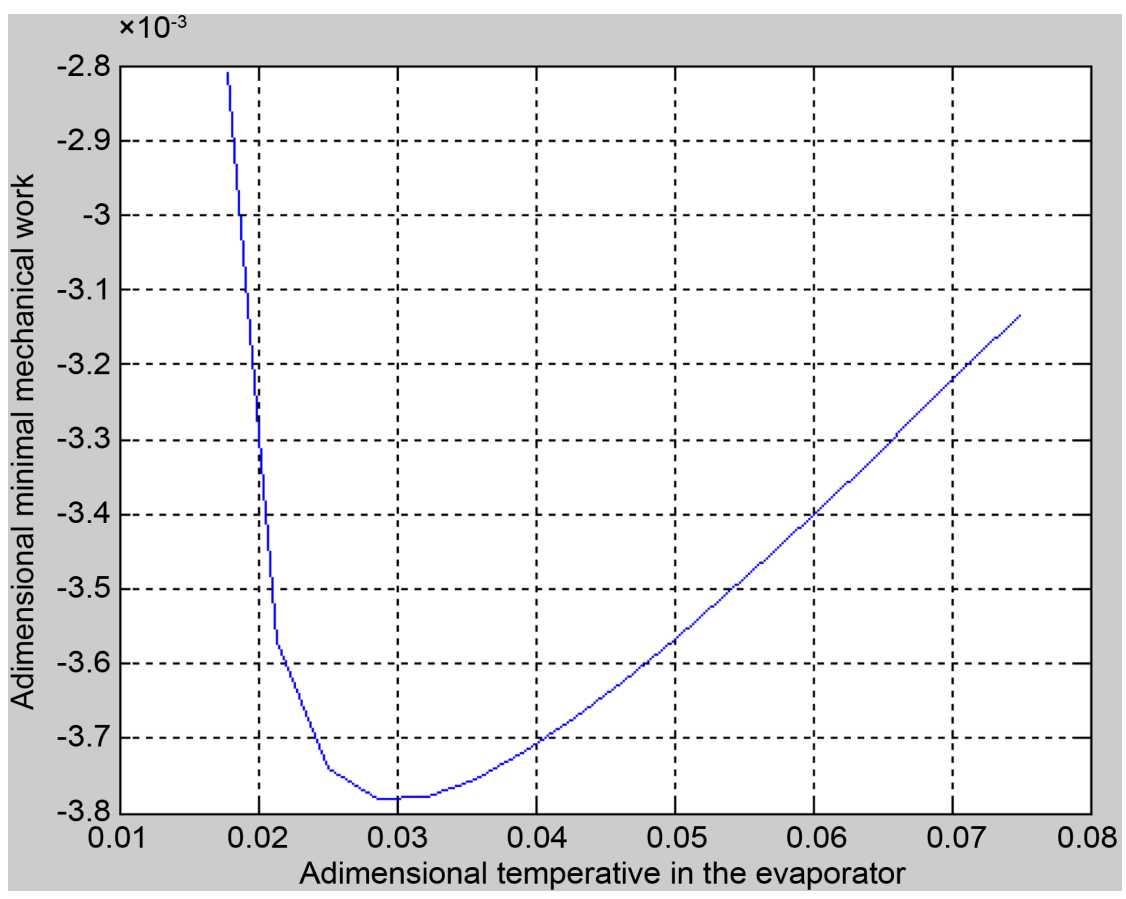

Figure 5. Evolution of a dimensional minimal mechanical work.

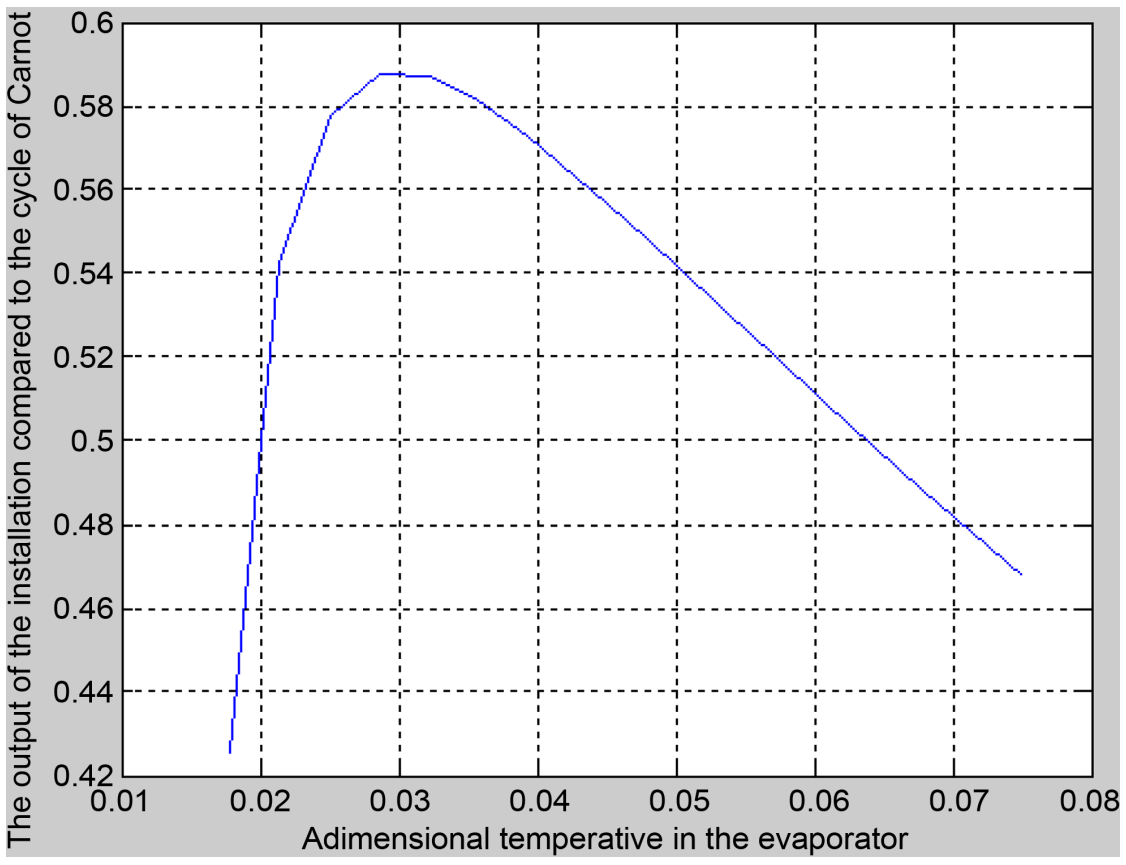

Figure 6. Evolution of the installation output compared to the Carnot cycle.

performance $\mathrm{COP}_{c}=\frac{\dot{Q}_{0}}{W}$ becomes null. If this variation $\Delta T_{0} \rightarrow \infty$, energy consumption $W$ to obtain is very high, the coefficient of performance is also null. To maximize the coefficient of performance in our case means a minimal consumption of energy $W_{\min }$ (Equation (35)). Optimization will consist in determining the optimal variation of 


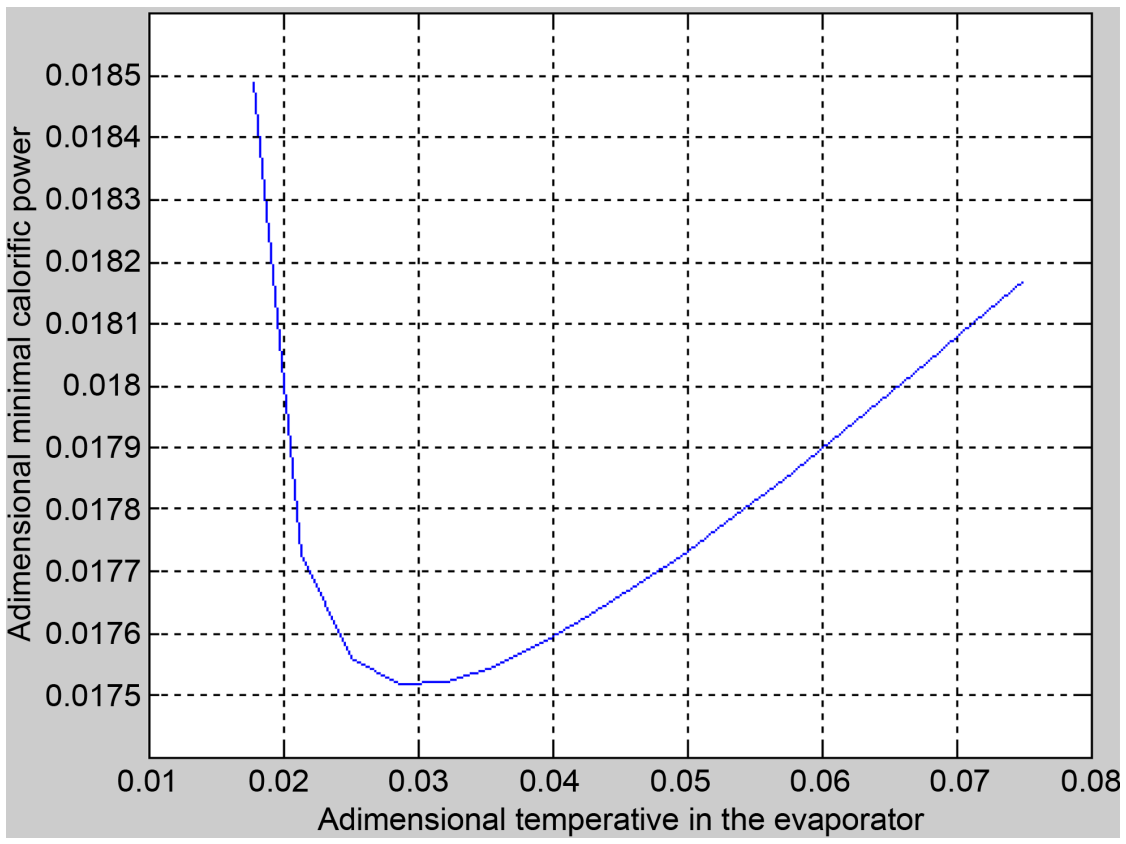

Figure 7. Evolution of the dimensional minimal calorific power.

evaporator temperature corresponding to a consumption minimal of energy for obtaining flow. In substituent the dimensional optimal temperature $\theta_{0}^{\mathrm{opt}}=2 \bar{Q}_{0}$ in Equations (15), (17), (25) and (28), we obtain the curve maximum of the real coefficient of performance (Equation (36)) and the minimum of the a dimensional mechanical work curve (Equation (35)); respectively Figure 4 and Figure 5. The expression (34), watch that the minimum of curve of a dimensional mechanical work corresponds at least of the dimensional calorific power curve (Figure 5 and Figure 7), since the refrigerating power is a constant. That is simply explained by the fact why the heating energy evacuated with the condenser decreases or increases when the work consumed by the compressor decreases or increases. With regard to the output of the installation compared to the cycle of Carnot Figure 6, its pace is similar to that of the coefficient of performance of the real cycle of the installation, for the simple reason that in the report, the denominator is invariable.

\section{Conclusion}

It goes without saying we always seek to obtain a better coefficient of refrigerating performance of the installation while keeping in mind that it should not exceed its theoretical maximum with knowing the coefficient of performance of Carnot. It should be noted that in practice, it was noted that when the cold stores function out of their optimal operating range, they see their refrigerating power decreased because of internal and external irreversibilities. Those can even reduce the coefficient of performance to zero, thus the cold store is then likely to function without producing refrigerating power (exactly like a disconnected car). The optimal operating ranges obtained in our study (Table 1) are: for the evaporator and respectively for the condenser, a coefficient of 
Table 1. Summary of the digital application of the optimization of the power station to ice-cold water.

\begin{tabular}{cc}
\hline Technical data of the installation & Got results of optimization \\
\hline$\dot{Q}_{0}=497.6 \mathrm{~kW}$ & $\theta_{0}^{\mathrm{opt}}=0.02994$ \\
$\dot{Q}_{c}=666 \mathrm{~kW}$ & $\Delta T_{0}^{\mathrm{opt}}=8.38 \mathrm{~K}$ \\
$K=118.657 \mathrm{~W} / \mathrm{K}$ & $\theta_{c}^{\mathrm{opt}}=0.03184$ \\
$T_{f}=280 \mathrm{~K}$ & $\Delta T_{c}^{\mathrm{opt}}=9.8 \mathrm{~K}$ \\
$T_{a}=308 \mathrm{~K}$ & $\bar{W}_{\min }=0.00254$ \\
$\mathrm{COP}=2.95$ & $\dot{W}_{\min }=84.6 \mathrm{~kW}$ \\
& $\mathrm{COP}_{\text {ir } \max }=5.88$ \\
& $\eta_{i}=58.8 \%$ \\
\hline
\end{tabular}

performance 5.88. This coefficient of performance is largely higher than that is presented by the manufacturer 2.95 , for the simple reason that in our study we do not take account of the losses caused by the internal irreversibilities. Lastly, to guarantee an optimal operation of the installation, the system of regulation of this one will have to be programmed according to the points of instruction of the optimal operating ranges.

\section{References}

[1] Grosu, L. (2000) Contribution à l'optimisation thermodynamique et économique des machines à cycle inverse à deux et trois réservoirs de chaleur. Thèse de doctorat, Institut National Polytechnique de Lorraine, Université Polytechnique de Bucarest et Nancy.

[2] Radcenco, V.T. (1994) Thermodynamique généralisée. Editura technica, Bucarest.

[3] Tables et digrammes pour l'industrie du Froid. Institut international du Froid Juillet 1991.

[4] Jean-Noël, F. and Julien, E. (2005) Thermodynamique, Base et Application Dunod Paris.

[5] Doumenc, F. (2009) Elément de thermodynamique et thermique. Université de Paris VI 2009.

[6] Mathilde, B. (2013) Reconsidération du moteur de Carno. Université de Lorraine, Nancy.

[7] Radcenco, V.T. (1992) Eléments de thermodynamique généralisée, irréversibles en temps fini et vitesse finie. Institut polytechnique de Bucarest.

[8] Okotaka Ebale, L. (1994) Contribution à l'étude de l'optimisation des systèmes de conditionnement de l'air. Thèse de doctorat, Université Polytechnique de Bucarest.

[9] Institut international du froid (Ed.) (1990) Le froid et les CCF, compte rendu du colloque international de Bruxelles 1990.

[10] Grosu, L., Feidt, M., Benelmir, R., Radcenco, V. and Dobrovicescu, A. (2000) Synthèse et perspectives des travaux relatives à l'étude thermo-économique des machine à cycle inverse. ENTROPIE no. 224/225, p. 11-18.

[11] Grosu, L., Rochelle, P. and Martaj, N. (2000) Thermodynamique à échelle finie et optimisation du cycle de Stirling. Institut polytechnique de Lorraine, Ecole Doctorale: PROMENA 2000, Nancy. 


\section{Nomenclature}

$A$ : Heat-transferring surface

$A_{c}:$ Surface of the condenser

$A_{0}$ : Surface of the evaporator

BEAC: Bank of the States of Central Africa

BP: Low pressure

COP: Coefficient of performance

$\mathrm{COP}_{c}^{\text {irr }}$ : Coefficient of performance of end or eversible but exoirréversible Carnot

$\mathrm{COP}_{c}^{r}$ : Coefficient of performance of end or eversible and exoréversible Carnot

$\Delta T_{c}:$ Variation in temperature to the condenser

$\Delta T_{0}:$ Variation in temperature with the evaporator

$\Delta T_{s c}:$ Variation in temperature of the superheater

$\Delta T_{s r}:$ Variation in temperature to the subcooler

$\Psi$ : Function

$\Psi_{\max }$ : Maximum of the function

h: Enthalpy

HR: Relative humidity

$K$ : Coefficient of total heat exchange by convection

$K_{c}$ : Coefficient of heat exchange by convection with the condenser

$K_{0}$ : Coefficient of heat exchange by convection with the evaporator

$\bar{K}_{0}$ : Coefficient of a dimensional heat exchange by convection with the evaporator

$\bar{K}_{0}^{\text {opt }}$ : Coefficient of optimal a dimensional heat exchange by convection with the evaporator

$m$ : Mass throughput

$P$. Pressure

$P_{c}:$ Pressure of condensation

$P_{\max }:$ Maximum power

$P_{\min }:$ Minimum power

$P_{0}:$ Pressure of vaporization

PMB: Dead bottom centre

PMH: Not high dead

$q_{c}:$ Calorific production

$\bar{Q}_{c}^{\text {min }}$ : Heat a dimensional minimal with the condenser

$\dot{Q}_{c}$ : Calorific power with the condenser

$q_{0}$ : Refrigerating production

$\theta_{c}$ : Heat a dimensional with the evaporator

$\Delta S$ : Difference in entropy

T: Temperature

$t$ : Time of contact of the fluid with the exchangers (evaporator and condenser)

$T_{a}$ : Room temperature, outside

$t_{a e}:$ Inlet temperature of air

$t_{a s}:$ Temperature of exit of air 
$t_{c}:$ Temperature of condensation

$T_{f}$ : Refrigerating temperature in the cold room

$t_{0}$ or $T_{0}$ : Temperature of vaporization

v. Specific volume

$W$ : Consumed mechanical energy

$\dot{W}$ : Mechanical power

$\bar{W}:$ Mechanical power a dimensional with the compressor

$\bar{W}_{\text {min }}$ : Mechanical power a dimensional minimal with the compressor

Submit or recommend next manuscript to SCIRP and we will provide best service for you:

Accepting pre-submission inquiries through Email, Facebook, LinkedIn, Twitter, etc. A wide selection of journals (inclusive of 9 subjects, more than 200 journals)

Providing 24-hour high-quality service

User-friendly online submission system

Fair and swift peer-review system

Efficient typesetting and proofreading procedure

Display of the result of downloads and visits, as well as the number of cited articles

Maximum dissemination of your research work

Submit your manuscript at: http://papersubmission.scirp.org/

Or contact jectc@scirp.org 